\title{
David Wang \\ Towards a New Virtualist Design Research Programme
}

\begin{abstract}
This paper considers how the influence of computer-cyber networks informs a new way of seeing on the part of designers as well as design researchers. In an adaptation of the notion of "virtual realities" made possible by computer technology, this new way of seeing is termed the New Virtualism. The INTRODUCTION suggests that this computer-cyber way of seeing is only the third paradigm shift in Western architectural history, following design predicated on the paradigm of the human body (1) and the machine (2). These three paradigms, following Tzonis and Lefaivre, are termed epiphores. After the introduction, PART I outlines implications of New Virtualist ways of seeing as expressed design trends, in terms of style. This is followed by PART II, in which is addressed seven ways New Virtualism can impact design research. The paper suggests that, while cyber technology vis-à-vis design might encourage some excesses of expression, cyber technology vis-à-vis design research actually helps to return design inquiry to constructs previous to the positivism inherited from the Enlightenment outlook. In other words, a New Virtualist design research programme can accommodate the qualitative aspects of design research more comfortably than the science-based positivism derived from the machine epiphore. This in turn promises new qualitative horizons for design research.
\end{abstract}

Keywords: New Virtualism, design, design research, epiphore

\section{Introduction}

About five years ago, in an article written for a general readership, I coined a term, the New Virtualism, to denote stylistic trends in current architectural design. The term referred to the influence of computer-cyber networks on how designers conceive of, and realize, physical forms (Wang, 2008). The five years since have strengthened my view that this term is apropos, not only for design praxis but now also for design research. In just October of this year (2012), I delivered one of the keynote lectures at The $4^{\text {th }}$ Symposium on Architectural Research and Competitions in Finland: Architecture as Human Interface in Helsinki, Finland. I spoke on the implications of the New Virtualism for design research. This current paper for FORMakademisk develops the ideas I presented in Finland, but refined in light of the kind critiques of colleagues and participants at the symposium.

In what follows, Part I defines what I mean by the New Virtualism, and I offer some suggestions for how it manifests itself in design. This section concludes with some concerns about these characteristic traits. Part II addresses New Virtualism vis-à-vis research. I will suggest that cyber technology, whatever its excesses might be when expressed (currently) in design, is better as an immediate fit for design research in that cyber technology can make more rigorous some of the qualitative approaches in this domain. I will also suggest that cyber technology might be able to recover for design, as a whole, what Alberto Perez-Gomez (2004) called the loss of mythos in his Architecture and the Crisis of Modern Science.

\section{Part I: New Virtualist Design}

\section{Epiphores and ways of seeing}

The computer is revolutionizing how humans relate to nature, which is to say, how the human constitution itself is understood. This is what interpretations of nature have always produced in 
the arena of design theory. In Classical Greece, the human body was held to be the nexus between natural and divine proportions, and this conviction was reified in the architectural Orders (Pollitt, 1972; Summerson, 1966; Vitruvius, 1960). By the heyday of the Industrial Revolution, the Machine not only reinterpreted architecture as a mechanical reality, but the human body itself was also re-conceived of as a mechanism. In turn, cities and houses all became "machines for living in" (Le Corbusier, 1986). Similarly today, cyber technology, with the computer as the iconic physical object, once again stretches how "nature" can be understood; the present article entertains suggestions and implications for design, but particularly for design research.

In an article published in 1975, Alexander Tzonis and Liane Lefaivre wrote of the shift from the human body to the machine as the epiphoric objects upon which architectural design was based. Tzonis and Lefaivre (1975) defined an epiphoric object as one that

impose(s) in a non-explicit manner the limits of the conceptual frame-work within which design ... can take place meaningfully. They are everyday objects. ... By accepting an epiphoric object ..., one accepts a conceptual framework in its entirety, which means not only an idea of the work as it is, but also as it can be and should be. (pp. 4-7)

In the periods regulated by these objects, not only were buildings unreflectively viewed first through the lens of the BODY, and then through the MACHINE; these epiphoric objects also gave sustenance to the overall worldviews of cultures in those periods. For instance, from the Parthenon atop the Acropolis to the Tempietto in Rome, we see human proportions as the paradigmatic framework for design. In contrast, in the Eiffel Tower and the Villa Savoye, the machine is the regulating epiphore. An epiphoric object, then, dictates how a person-but more to the point, how an entire culture - unreflectively sees the cosmos, and then translates that view into the design of things for daily use.

However, Tzonis and Lefaivre's article appeared in 1975. At that time, they wrote only of two epiphores, the body and the machine. (They were interested in the shift from the earlier to the latter epiphore in the context of the French academic scene at the dawn of the Industrial Revolution). However, now, for only the third time since the Greeks, a new epiphore is emerging: the COMPUTER. The computer is more than just another machine; what this machine enables is far beyond anything the Industrial Revolution was able to provide, or even to imagine.

The computer acts as a portal to an entirely new cyber-world, with the following implications. The computer-cyber epiphore redefines distance: For the first time in history, people the world over can truly be connected instantaneously. Thus, the computer-cyber epiphore redefines time: Michael Speaks (2005) has suggested that "theory" itself may be a thing of the past, since rapid prototyping technology erases the time lapse between thinking (theoria) and realization (praxis). Furthermore, the computer-cyber epiphore redefines scale: At the macro scale, entire islands in Dubai are materialized with computer-driven equipment; at the micro scale, we now envision computers in our bodies in lieu of computers around us (Neurogadget, 2012). Finally, the computer-cyber epiphore redefines function. Consider all of the uses packed into the tiny "smart" phone: camera, alarm, calendar, photo album, music player, GPS, language translator, to name only a few. The physical attributes of the object itself offer no clues that it can perform these functions. In the brave new world of the computer-cyber epiphore, form does not follow function. 
Thus, by the New Virtualism I mean the following:

The driving force (or instinct) behind the design of objects of all scales that essentially derives from how cyber technology is redefining the human relationship to nature. This driving force, or instinct, is subsumable in the object of the computer, not in the sense of its physical dimensions, but in the sense of its paradigmatic form emphasizing its cyber connectivity. Following Tzonis and Lefaivre, this computer-as-paradigmatic object is called the computer-cyber epiphore, and its varied influence on design and research is termed the New Virtualism.

By "virtualism," then, I mean to evoke the term often mentioned these days in simulation research: "virtual reality." Thus, I do not mean "virtual" in any moral sense, as in virtuous. I mean the capacity of cyber technology - and we are still at the beginning stages of how this technology will ultimately impact life as we know it - to create "realities" that are not indexed to the physical, perhaps orthogonal and fixed, dimensions that were associated with the machine. The New Virtualism is driven by the desire to create new, which is to say novel, realities birthed from cyber-informed imaginations. Hence, the New Virtualism.

Now, as is the case with design in any historical period, New Virtualist design results in a "style," if by this word we mean a wide diversity of formal attributes that are nevertheless intuitively discernible as bearing a "family resemblance" to one another. The human body epiphore yielded buildings having feet, body, and head (consider the Classical column: base, shaft, capital/cornice). The machine epiphore first celebrated machined components evoking vastly increased power in relation to the human body (e.g., the Eiffel Tower); it then led to the machined surfaces - and the rejection of ornament — of the International Style. The next section itemizes some visual attributes of New Virtualist design style.

\section{Design in the cyber sea: key design characteristics of the New Virtualism}

A point I made in my earlier article is that architects always "swim in the sea" of the worldview of the dominant epiphore (Wang, 2008, p. 34). Just as Bramante (architect of the Tempietto) and other Renaissance architects unreflectively produced architectural forms aligned with the human body epiphore, just as Modernist architects unreflectively produced forms after the machine epiphore, today, architects unreflectively design buildings informed by what they imbibe in the cyber sea.

The easiest way to emphasize this point is to recall what Thomas Kuhn said about how scientists work under an established research paradigm. For instance, during the era when the ruling Ptolemaic paradigm held that the sun revolved around the earth, scientists did not question that view; they just conducted research to ratify it (Kuhn, 1962). Similarly, architecture of any era is produced in accordance with the epiphore that regulates the era, and the visual attributes of designed objects ratify the worldview of the epiphore (Wang, 2009).

Consider Herzog \& de Meuron's Bird's Nest stadium in Beijing. The lacey strands that make up this "nest" bear striking resemblance to graphically depicted maps of the World Wide Web (WWW). The countless curvy strands graphically representing a map of the WWW not only chart seemingly endless cyber linkages "out there"; these strands are also in us, and they go through us. The form of the Bird's Nest is an outgrowth of the unreflective way of thinking and seeing fueled by the cyber epiphore. Just as the human body epiphore cultivated buildings conceived of as a reflection of human proportions, just as the machine epiphore cultivated an attitude that nature can be conquered by steam shovels and locomotives, swimming in the cyber 
sea yields an instinct that human negotiations with nature need not be orthogonal. They need not be planar; they need not be seamed. Instead, they can be something like the form of the Bird's Nest: porous, endlessly flexible, with curved things going through other curved things in wonderful complexities.

Again, the aim of Part II is to enumerate implications of the New Virtualism for design research. But let me first summarize some of the design characteristics of the New Virtualismin other words, the characteristics of New Virtualist style. This preliminary step is important because I will suggest that a New Virtualist research approach might be able to rectify - perhaps once again to humanize - some of the more excessive overreaches of New Virtualist design.

First, New Virtualist design is asomatic. By this, I mean it is not indexed to the human body. Go to the National Aquatics Center (the "Ice Cube") in Beijing, and you will be hard pressed to find the front door. This same diminution of human entry is also found at OMA's Seattle Public Library. Or again: take one look at the D-Tower in Doetinchem, the Netherlands, and you have the sense of the presence of something other than human. I will return to this problem in the research section below.

Second, New Virtualist design is mutliplexic. The best way to put this has been noted above: Form does not follow function in New Virtualist objects and buildings. How could form follow function when the nature of New Virtualist objects is to perform many seemingly unrelated functions, some of them all at once? Earlier, we noted the many functions performed by the smartphone. As a matter of fact, the total number of "apps" for the smartphone is too long to list. And the object itself does not "look like" any of these functions.

Third, New Virtualist design is placeless. Because the multiplexic powers of New Virtualist objects are cyber-enabled, they can function anywhere independent of local restraints and resources. At the scale of buildings, OMA's theory of "Bigness" is perhaps a symptom of this placeless aspect. Today's cyber-connected buildings cannot be limited to respond only to their physical-local contexts; their "site" is globally extended. Hence, Bigness (OMA, Koolhaas, $\&$ Mau, 2008). As a result, OMA's CCTV Tower in Beijing and the Seattle Public Library are two buildings that are interchangeable insofar as physical location is concerned. Both are global — which is to say, placeless_-buildings.

Fourth, New Virtualist design offers the illusion of sentience. These days, we not only want to use the objects around us; we also want to have a relationship with them. GPS devices talk to us in attractive, even vaguely sexy, voices (e.g., "in half a mile, exit on So-and-So Road, then keep left ...”). Numerous online sites (e.g., Amazon.com) know our preferences, and tell us what we'd like to purchase before we can think of those things ourselves. Recently, the BBC featured the vision of an entire city likened to a nervous system, wired with sensors all interconnected to smartphones, so that real-time responses to all events are possible. Street signage, for example, can automatically redirect traffic during an emergency. Another example is users remotely controlling home appliances. All the demands of life are addressed on a realtime basis because a city - and hence city life - is more akin to the operations of an organism rather than that of merely an organization (Moskvitch, 2011).

Thus, fifth, New Virtualist design features distributed ontology. In the human body and machine epiphores, objects were designed with discrete physical forms/boundaries. But increasingly design seems to involve systems rather than objects. The movie distributor Netflix recently rendered obsolete the previous model for marketing movies: Blockbuster. While the earlier operation was centered on a building one has to drive to and park at (thus requiring a 
chain of physical objects and the fossil fuels required to maintain them), Netflix has no location per se, at least in terms of its presence to the consumer. One can say that Netflix has a distributed ontology. This is also true of Facebook as a place for cultivating "community." Certainly the city-as-organism is an example of distributed ontology. More and more, distributed ontology characterizes the nature of services once requiring physical objects and venues. $^{1}$

Now, these features of New Virtualist design-diminution of the human body, placelessness, form not indexed to function, distributed ontology (thus without physical form), certainly the "sentience" of material objects from GPS devices to entire cities-might raise concerns. After all, we remain embodied human beings, and daily life still engages intimately with the attributes of physicality: tactility, aromas, sights and sounds, the weather, daytime and nighttime, in short, locale (Frampton, 1987). ${ }^{2}$ Even in light of obvious benefits such as energy savings when products and services are delivered virtually, the loss of simple human interactions, from which issues community, might be a deficit the extent of which has not yet been fully appreciated.

It might be that some of the exuberant variety of current New Virtualist design is an overreaction to the dogmatic confines of Modernism's commitment to the machine, with its emphasis on utility and machined regularity. (The Postmodernist period was also a casting off of Modernist restraints). Before the restrained lines and planes of twentieth-century Modernism, all derived from reference to the machine (Le Corbusier, 1986), we might recall that the early stages of the Industrial Revolution also featured examples of excessive celebration of the machine epiphore, for example, exorbitant size (e.g., Boullée's Metropolitan Cathedral) or excessive celebration of function (e.g., Ledoux's Saltworks, 1770s; not to mention his phallus-shaped House of Pleasure, also 1770s).

But this is where we are vis-à-vis New Virtualist design, and it is difficult to prognosticate what a more "restrained" use of cyber capacities might look like as designers continue to swim in the cyber sea. As we turn to design research, I will suggest that cyber technology, in fact, might be more immediately compatible with the human-based research that has always characterized design inquiry. Thus, a New Virtualist research agenda might just give design research the qualitative gravitas it has struggled to achieve prior to the advent of the computer. Ultimately, this might also influence how New Virtualist design is realized as well, in perhaps a more restrained, humanly accommodating, manner.

\section{Part II New Virtualist Design Research}

\section{The machine-based positivism of "research" and its problems for design inquiry}

Let me first suggest that current standards of research rigor are essentially derived from a positivist outlook that emerged out of the same Enlightenment developments that gave us the machine epiphore. For research under this epiphore, "scientific method" is the path to true knowledge; all other claims to knowledge are, well, somewhat less robust. These standards of research rigor are well-known: experimentation, measurability, empirical verification, replication, statistical significance, "objectivity." It is not that these standards are off the mark (far from it!); it is that they tend to overly define what all research must consist of. This hegemony has resulted in something of a divide in the academy between those who engage in discipline-specific knowledge largely compatible with the positivist outlook and research in the design disciplines, which tends to be more interdisciplinary and qualitative. 
In the Nordic countries and more generally in Europe, Halina Dunin-Woyseth and her colleagues (2008, 2011a, 2011b) have led the way in efforts to broaden design education by defining it from a practice-based (that is, a profession-based) way of knowledge production. ${ }^{1}$ And the practice of architecture and related design disciplines necessarily engages qualitative dimensions of human social behavior. Cyber technology delineates systems of human behavior as candidates for design, and this ushers a qualitative aspect right into the domain of rigorous research. For example, one researcher found that creating "spirit" is one necessary dimension for online classrooms to maintain enrollment (Rovai, 2002). ${ }^{3}$ This is knowledge of a qualitative sort that has traditionally been the focus of research in the design disciplines. In the following categories, I argue that the computer-cyber epiphore is inherently more accommodating of some of the qualitative emphases that have always characterized design inquiry.

\section{New Virtualist design research emphasizes projections in lieu of predictions.}

The emphasis upon predictive power in research of any kind is itself a product of Enlightenment science. It assumes that we have true knowledge only when we can predict future occurrences of the object under study. However, prediction is largely dependent upon experimental research, and my co-author of Architectural Research Methods, Linda Groat, has noted the limitations of this mode of inquiry: It reduces complex realities to a few independent variables, and its overemphasis on control might result in ethical limitations as well as dehumanization (Groat \& Wang, 2002).

Cyber technology, in contrast, accommodates a plethora of variables such that computer simulations of "reality" approach the complexity of the actual world. Rather than being reductive, cyber technology forges new ways of inclusivity in research designs. We see this in such computer programs as UrbanSim, which simultaneously accounts for the actions of households and businesses, government processes, land use inputs, and market forces, to list a few, in a single interactive model of urban morphology and life "designed to maximize reality" (UrbanSim, 2009).

The outcome of these kinds of simulations is more projections than predictions. Projections are by nature more inclusive of human interactions; projections deal in what can happen, in contrast to experiment-based predictions of what must happen as a result of manipulated variables. Now, what is interesting about projection is that it harks back to a more qualitative way of knowing, one that predates the positivist outlook by more than a millennium. I am thinking of the Aristotelian notion of poetry as contemplation of what can happen. The poet takes into account all inputs of a situation and suggests a "universal" outcome that is nevertheless not fiction, but based upon a reasoned consideration of all possibilities (Aristotle, Poetics, § 9). The point is that similarities between poetic projection and cyber projection are striking. The latter allows for an inclusive accommodation of human freedom. In this sense, a computer-cyber approach to research not only accommodates inquiry by praxis, but also praxis results in a projective kind of knowledge that retains the qualitative human dimension. ${ }^{4}$ 


\section{New Virtualist design research is informed by simultaneity.}

By simultaneity, I mean the ability of the computer to blur distinctions, for instance, between theory versus practice, or discipline versus profession. Research rooted in the previous machine epiphore thinks in distinctions, e.g., the sciences versus the arts. Under these distinctions, for instance, Nigel Cross (1995) felt the need to classify design thinking as its own unique category of intelligence. But swimming in the cyber sea of the computer epiphore yields research that may not root itself in traditional divisions of knowledge. For example, one day at the University of Pennsylvania, a cellular biologist happened to be strolling along to get a cup of coffee when he happened by a conference held at the School of Design's Non-Linear Systems Organization (NSO). The conference question: "How can scientific models of complex phenomena in mathematics ... be most effectively employed in the design and fabrication of structures for human life and enjoyment?" The biologist was "blown away" by the striking parallels to his work. This resulted in exchanges between the two seemingly distant disciplines (Popp, 2009). The computer blurs distinctions between disciplinary silos because it addresses issues at a substrate level of cognition, a level having to do with similarities, metaphors, shared intuitions of likenesses between things, where "structure" has to do with the very fabric of reality before it puts on different costumes for different disciplines.

We already noted Michael Speaks' point that computer technology erases the divide between theory and practice in that theoria can be instantly realized, for instance, by rapid prototyping (praxis). Speaks' logic has limitations because he is theorizing just by stating his point; hence, theory remains its own distinct domain. But this aside, cyber technology indeed blurs the gap between iconic theories applicable across generations, versus episodic explanatory frameworks having specific applications. (Temporally) localized theory seems to be more apropos under the cyber epiphore. This creates a connection between design theories and grounded theory in the social sciences, in which a researcher engages in "development of theory without any particular commitment to specific kinds of data, lines of research, or theoretical interests" (Strauss, 1987, p. 5). That is to say, the researcher allows the facts of a particular case to yield the needed data. Thus, design researchers, via cyber technology, have common ground with social science researchers in appeals to research rigor.

Simultaneity is also seen in the blurring of lines between discipline and profession. Consider this from Ken Friedman:

one studies the disciplines that lead to professional practice -- design, law, medicine, etc. Once embarked in professional practice, one is not engaged in a discipline but in a profession or a field. If one goes back for advanced study or to teach, one returns to the discipline. (personal communication, September 29, 2007)

However, the rise of online education prompts reevaluation of Friedman's distinction between profession and discipline, which implies that an individual is in one or the other at any one time. In the U.S., the number of online courses has seen a meteoric rise in the last five years, some of this driven by returning professionals for continuing education (Allen \& Seaman, 2007). The implication is that profession (praxis) must be simultaneous with theoria (discipline) if it is to keep abreast of rapidly advancing knowledge. This vastly increases opportunities to integrate the silos of practice and academic research into one domain. 


\section{New Virtualist design research emphasizes democratic participation.}

Simultaneity in the cyber epiphore also blurs the traditional separation between designer and user. Threadless.com, an online vendor of T-shirts, asks its customers to submit designs online. "Make great ideas, share them with the world, earn fame and fortune, we've awarded over $\$ 6$ million to artists," says the website (Threadless.com, n.d.). Akin to the difference between prediction, which involves reductive experimental processes, and projection, which is accommodational and inclusive, cyber technology enables participatory design that democratizes the entire design process. Design research must evolve new tactics in which direct citizen participation is no longer merely on the level of statistical samples. Rather, participation yields the outcomes themselves. The researcher becomes more of a facilitator than an analyst-even though the facilitating instruments (such as the Threadless.com website) must necessarily be designed to yield robust results.

But if democratic participation is itself the outcome of research, then the platform for that participation - that is, the computer and the cyber connections it enables-is not itself an artifact per se. The platform is more like the air we breathe, or perhaps the space in which we live. A recent study found that the "Net Gen" generation of young people (those born between 1982 and 1991) consider the Internet "oxygen . . . they can't imagine being able to live without it" (Oblinger \& Oblinger, 2005, p. 2.9). And so this from Mark Poster (2001):

The internet is more like a social space than a thing, so that its effects are more like Germany than those of hammers: the effect of Germany upon the people within it is to make them Germans ... the effect of hammers is not to make people hammers ... but to force metal spikes into wood. (pp. 176-177)

If this citation sounds strange, it is only because we are confronted by a technological innovation that has transcended object-tivity. The innovation is now a system, and the effects of this system are so vastly extended that its ontology can be likened to a social space (such as, in Poster's example, a nation). If indeed this system is a social space, then experimental science is perhaps not the only basis for research inquiry in comprehending this domain. If indeed this system is a social space, then all of the qualitative research methodologies used to study social interactions come more to the fore.

\section{New Virtualist design research concerns the design of systems rather than (or in addition to) the design of objects.}

In Part I, we noted that New Virtualist designs feature a distributed ontology, and cited the example of an entire city conceived of as an organism. More and more, our lives are enabled by systems rather than by objects; an object such as the cell phone is deceptive in this regard, since a cell phone is useless without the vastly extended cyber networks that enable its operation(s). From shopping to banking to learning to access for news, all of these services come to us via distributed networks. These days, even the pleasure of getting lost is no longer available to us (e.g., the OnStar system). Even romance comes via the Internet (e.g., eHarmony.com). A recent Economist Special Report identifies three ways the cyber world interacts with the physical one: 1) the digital realm reshapes the physical realm, as in distributed office locations, online shopping, and the like; 2) the digital realm offers a separate world from the physical one, as in online games in which players distributed across the world interact simultaneously; and 3) 
physical demands also influence the digital world, as in "apps" that identify the distribution of tables available at local restaurants ("Technology and Geography," 2012).

All of this calls for design research to attend to the form of systems rather than the physical forms of objects. For instance, how to design a system of shared vehicles, the locations of which are all mapped onto smartphones, to service an urban area? Or how to design a service for companies to hire office workers on an on-demand basis, all via cyber connections ("Technology and Geography," 2012)? How does one design a "sense of community" for distance participatory venues such as classrooms or "virtual townhall" meetings? These are examples of the kinds of question design research under the New Virtualist epiphore should ask. It is about the design of systems, not (only) the design of objects.

\section{New Virtulist design research blurs Simon's inner versus outer worlds.}

Herbert Simon's Sciences of the Artificial can rightly be hailed as one of the beginning salvos of the computer revolution. However, when Simon published his work in 1969, perhaps even he did not fully appreciate what would become of his distinction between the "inner" versus "outer" environments. By this distinction, Simon meant to say that any artifact-and all human innovations are arti-factual - has an inner constitution in contrast to the constitution of the outer environment within which the artifact needs to function. A clock on a ship at sea, an airplane flying in the sky, a production schedule that optimizes return for investment; all these artifacts have inner environments interfacing with their outer environments (Simon, 1996). Simon held that we do not have to exhaustively know about each inner/outer environment; we need to know only enough about the interface to ensure that the performance of an artifact would "satisfice."

But what if the entire environment is itself artifactual? As design focuses on systems, the scale of the systems at least calls for a reevaluation of Simon's distinction. When we "swim" in intricate webs of global Internet connections, when we live in cities-as-themselves-organisms, the distinction between inner and outer environments loses focus. At the micro level, cell-sized computers in our bodies simulate disease scenarios, adjusting the body's workings to avoid such illnesses (Neurogadget, 2012). At the macro level, consider the Corning Glass videos that depict "A Day Made of Glass" in the near future. In the latest release, a medical exam room is entirely made of glass - which interfaces cybernetically with a corresponding room across the world. Physicians talk to each other through a transparent wall, fully seeing each other while a patient's data is displayed on the glass between them. The patient at the distant location is then transported as a three-dimensional actual-sized image to the local physician's examination table. Diagnostics of the patient's brain are projected into space for the doctor to see, at his eye level, in his exam room (“A Day Made," 2012).

It is frankly not clear what radical transformations of praxis such as this implies for design research, other than to say the obvious: It affects every aspect of design research. What happens when "video conferencing" approaches the tactility, and environmental fullness, of actual physical encounters, complete with the ability for participants to exchange physical items as if across a table? This implies entire buildings can be virtual, or at least just offer enough physicality to enable virtual presences all over the world. I have often said to my students that the world will radically change when we can fax a pizza from one location to another. (Roads and transportation networks will no longer be needed. What does that portend for neighborhoods, business districts, entire cities, etc.?). Here, a three-dimensional image of a patient is "faxed" across the world for treatment. Aside from what this implies for medical 
advances, what does it do for "sense of community"? For education? For business? For tourism? When the entire outer environment has become the inner environment of the cyberartifact, how does this change the way life has been lived on this planet up to now? Questions such as these open up enormous avenues for design research.

\section{New Virtualist design research concerns itself with a metaphysics of ornament.}

For the Greeks, the floral motifs on Corinthian capitals, the fluting on the columns, the entasis of those columns, were not ornament. Working under the human body epiphore in which every aspect of a building participated in a transcendent proportional order, the Greeks really had no idea what "ornament" was. The awareness of ornament, or decoration, was a result of the advent of the machine. The machine epiphore created the divide between what was essential and what was ornamental, or non-essential. Essential was structure, functional utility, economic logic, geometric orthogonality, so on. By the time of Adolf Loos, Ornament is Crime (!). And for Mies van der Rohe, "Less is More."

However, the cyber epiphore restores (what has been called) ornament back to an essential dimension of design. This is different from ornament under Postmodernism. In that earlier phase, ornament simply erupted as liberation from the austere strictures of Modernist dogma (and so Venturi: "Less is a Bore!"). But look at any map of the World Wide Web, and we see a cyber-entity the twists and turns and convolutions of which are essential to its very nature; yet the possibilities for these elaborate forms seem to be endless vis-à-vis its power to inform (what a Modernist would call) ornamental expression. This research statement from Gramazio \& Kohler, Architecture and Digital Fabrication (n.d.), is representative of the reintegration of ornament into the essential logics of designed forms (italics added):

By positioning material precisely where it is required, we are able to interweave functional and aesthetic qualities into a structure. We can thus "inform" architecture through to the level of material. Our aim is to develop criteria for a new system of structural logic which can be applied to architecture and that is intrinsic to digital fabrication. We started with modules such as bricks as a basic material and are now expanding the spectrum to include fluid materials.

The design implications of this return to ornament-as-essence are obvious. Design research, for its part, can identify rubrics for determining whether any instance of ornament is, indeed, essential to the cyber logic generating a form; or whether cyber power is simply being used to create outlandish expressions that have nothing to do with the essential logic of the production at hand. Perhaps at a deeper level, with a return to (again, what the machine outlook calls) ornament, I suggest that the cyber epiphore can return architecture and built environments to an evocation of mythos.

\section{New Virtualist design research accommodates a return to mythos.}

Of architecture under the machine epiphore (or what he calls "modern science"), Perez-Gomez (1994) laments thus:

The poetical content of reality, the a priori of the world, which is the ultimate frame of reference for any truly meaningful architecture, is hidden beneath a thick layer of formal explanations. Because positivistic thought has made it a point to exclude mystery and poetry, contemporary man lives with the illusion of the infinite power of reason. He has forgotten his fragility and his 
capacity for wonder, generally assuming that all the phenomena of his world, from water or fire to perception or human behavior, have been "explained." (p. 4)

An overview of the trajectory of Western architecture emphasizes this point. Before the Enlightenment and its aftermath (read: the Industrial Revolution), architectural edifices sought to touch the transcendental realm. Whether it was the Platonic forms, or the realm of heaven in medieval Christianity, architecture was typically imbued with the power of mystery. The writer Alain de Botton (1996) speaks of an experience when, after a disappointing visit to a McDonald's restaurant, he went into Westminster Cathedral, where he "entered into a cavernous hall, sunk in tarry darkness, against which a thousand votive candles stood out, their golden shadows flickering over mosaics." He continues:

After ten minutes in the cathedral, a range of ideas that would have been inconceivable outside began to assume an air of reasonableness. Under the influence of the marble, the mosaics, the darkness ... it seemed entirely probable that Jesus was the Son of God and had walked across the Sea of Galilee. (pp. 109-111)

It is difficult to imagine this sort of epiphany in a building answering to the machine epiphore. But an edifice under the cyber epiphore might once again stir a sense of an encounter with mystery. Cyber technology deals in numbers - and scales - of such staggering sizes that it raises, in addition to mathematical questions, theological ones. Consider this from a recent article, "Is the Universe Just a Computer Simulation? Now, We Can Check":

pretend that you're a hyper-intelligent pan-dimensional being equipped with the sort of computer that hyper-intelligent pan-dimensional beings tend to have lying around. This computer works just like the computer that ... less-pan-dimensional humans are using to simulate a femtometersized region of the universe, except that, instead, it can simulate the whole damn thing. All of it. And that simulation would be impossible to distinguish from something "real." (Ackerman, 2012)

I am not suggesting that cyber technology can replace God; I am simply suggesting that cyber technology enables material expressions that were once driven by the human need for awe, for the sublime, for connections to the transcendent, in short, for all of the needs that somehow the positivism of the machine cannot (or can no longer) provide. I am simply saying that a New Virtualist design/research programme accommodates investigations into mystery, the sacred, and the sacramental.

\section{Conclusion}

These thoughts are by necessity speculative. But they are speculation based upon what we are obviously confronted with today: the enormous power of cyber technology and its iconic object, the computer. So vital has the computer become in today's globalizing culture (after all, the computer enables the globalization of culture), we can say that it has replaced the machine as the epiphoric object for design. That is to say, the powers of cyber technology now inform, not so much how designers think (which it surely does), but how they instinctually see "nature," and themselves in "nature." Designers today swim in the cyber sea, and the designs they produce reflect their imbibing of virtual realities. Hence, the New Virtualism. 
However, we are at the beginning stages of this Cyber Revolution. Just as it was difficult to imagine what the machine would bring at the beginning of the Industrial Revolution, it is now also difficult to imagine what the computer will ultimately bring. Any one reading this article can compare the computer's powers just five, ten, or fifteen short years ago with what the computer can do today. The advances have been immense. Yet our better instincts tell us these innovations will prove quite insignificant compared to where cyber technology will take us even fifteen years from now. In this new heyday, New Virtualist design exhibits the exuberance of youth, and this paper expressed some concerns over the tendencies to, for instance, not be indexed to the human form, to erase sense of place, to place the human being nowhere because cyber power is everywhere.

In contrast, a New Virtualist design research programme can play a role in balancing the excesses of New Virtualist design. In short, a research programme can add rigor to precisely the human dimension of life experience that current positivist-oriented research strategies sometimes relegate to a lesser status. A New Virtualist design research programme projectively includes elements of human freedom in contrast to the reductivist nature of positive prediction. A New Virtualist design research programme is better equipped to erase categorical distinctions (e.g., theory/practice, discipline/profession, designer/user) such that the outcomes of its inquiry tend to be more phenomenologically reflective of immediate social conditions. A New Virtualist design research programme welcomes a diversity of aesthetic expressions not as unnecessary add-ons to some core essentiality, but rather as essence itself. Hence, a New Virtualist design research programme can perhaps welcome a return to mythos.

Let me conclude with one recommendation for future research. Currently in the global zeitgeist, there seem to be two conflictive design movements, broadly speaking. One is what I have termed the New Virtualism, exemplified by such works as the CCTV Tower, the Seattle Public Library, the D-Tower, the Bird's Nest Stadium, and so on. The other movement we can term Green Design. Indeed, "sustainability" is now a byword recognized by architects and designers the world over, even though the term is difficult to precisely define. However, representative examples of this movement make the general intentions of the sustainable design agenda clear. I am thinking of such hallmarks as William McDonough's (2008) Hanover principles or McDonough and Braungart's (2002) Cradle to Cradle, Ken Yeang's books such as Green Design: From Theory to Practice (2011), Norman Foster's (2008) zero-carbon, zerowaste city of Masdar, Abu Dhabi, and so on. These two movements conflict because, while the latter stresses conservation of natural resources, the former's revelry in cyber-enabled forms tends not to respect green considerations. The CCTV Tower, for instance, has a mega-structural frame held up by untold tons of concrete at the foundation, and the building's mechanical system is enormous. How to blend these two conflictive movements into a single theoretical framework and praxis agenda? It strikes me that this is a critical question as architectural design, and design research, continues to make progress. Perhaps green awareness will ultimately lead architects to produce mature expressions of twenty-first-century architecture, even while they swim in the cyber sea.

\section{David Wang}

$\mathrm{RA}, \mathrm{PhD}$, Professor of Architecture

Washington State University

Email: davidwang@wsu.edu or david.wang.wsu@gmail.com 


\section{References}

Ackerman, E. (2012). Is the universe just a computer simulation? Now, we can check. Retrieved November 28, 2012, from http://dvice.com/archives/2012/10/is-the-universe.php.

A day made of glass 2: Unpacked. The story behind Corning's vision. (2012). Retrieved November 28, 2012, from http://www.youtube.com/watch?v=X-GXO_urMow.

Allen, I. E., \& Seaman, J. (2007). Online nation: Five years of growth in online learning. Sloan Consortium, 2. Retrieved November 19, 2012, from http://www.google.com/url?sa=t\&rct=j\&q=\&esrc=s\&source=web\&cd=1\&ved=0CFEQFjAA\&url=http $\% 3$ A\%2F\%2Fsloanconsortium.org\%2Fpublications \%2Fsurvey\%2Fpdf\%2Fonline_nation.pdf\&ei=SvirUPCXJ c_miwLbvIDgCA\&usg=AFQjCNEbfaKvqXOjBQy1LoIQv60eDLntig\&sig2=iFBX6a9sTXbMCKXNaKg OxA.

Cross, N. (1995). Discovering design ability. In: R. Buchanan \& V. Margolin (Eds.), Discovering design: explorations in design studies (pp. 116-117). Chicago: University of Chicago Press.

de Botton, A. (2006). The happiness of architecture. New York: Vintage Books.

Dunin-Woyseth, H., \& Nilsson, F. (2008). Some notes on practice-based architectural design research: Four 'arrows' of knowledge. In: A. Hendrickx, et al. (Eds.), Reflections +7 . Brussel-Gent, Belgium: Sint-Lucas Architectuur.

Dunin-Woyseth, H., \& Nilsson, F. (2011a). Building a culture of doctoral scholarship in architecture and design: A Belgian-Scandinavian case. Nordic Journal of Architectural Research, 23(1).

Dunin-Woyseth, H., \& Nilsson, F. (2011b). Building (trans) disciplinary architectural research-Introducing Mode 1 and Mode 2 to design practitioners. In: I. Doucet \& N. Janssens (Eds.), Transdisciplinary knowledge production in architecture and urbanism (pp. 79-96). : Springer.

Frampton, K. (1987). Towards a critical regionalism: Six points for an architecture of resistance. In: H. Foster, (Ed.), Postmodern culture (pp. 16-30). London: Pluto Press.

Gramazio \& Kohler, Architecture and Digital Fabrication, ETH Zurich Departement Architecture. (n.d.). Research. Retrieved November 28, 2012, from http://www.dfab.arch.ethz.ch/web/e/forschung/index.html.

Groat, L., \& Wang, D. (2002). Experimental and quasi-experimental research. In: Architectural research methods (p. 270). New York: Wiley.

Kuhn, T. (1962). Normal science and puzzle solving. In: Structure of scientific revolutions (pp. 35-42). Chicago: University of Chicago Press.

Le Corbusier. (1986). Towards a new architecture (F. Etchells, Trans.; pp. 4, 95, 107). New York: Dover.

Masdar. (2008). WWF and Abu Dhabi's Masdar initiative unveil plan for world's first carbon-neutral, waste-free, car-free city. In: H. F. Mallgrave \& C. Contandriopoulos (Eds.), Architectural theory. Vol. II: An anthology from 1871 to 2005 (pp. 601-603). Malden, MA: Blackwell.

McDonough, W. (2008). The Hanover principles. In: H. F. Mallgrave \& C. Contandriopoulos (Eds.), Architectural theory. Vol. II: An anthology from 1871 to 2005 (pp. 584-585). Malden, MA: Blackwell.

McDonough, W., \& Braungart, M. (2002). Cradle to cradle. New York: North Point Press.

Moskvitch, K. (2011, September 30). Smart cities get their own operating system. BBC News Technology. Retrieved November 18, 2012, from http://www.bbc.co.uk/news/technology-15109403.

Neurogadget. (2012). Implantable chemical circuits to build computer chips that directly interface with human cells. Retrieved May 12, 2012, from http://neurogadget.com/2012/05/31/implantable-chemical-circuits-to-buildcomputer-chips-that-directly-interface-with-human-cells/4397. 
Oblinger, D., \& Oblinger, J. (2005). Is it age or IT: First steps toward understanding the Net generation. In: D. Oblinger \& J. Oblinger (Eds.), Educating the Net generation. EDUCAUSE. Retrieved January 1, 2012, from http://www.educause.edu/educatingthenetgen/.

OMA, Koolhaas, R., \& Mau, B. (2008). "From 'Bigness,' or the problem of large.” In: H. F. Mallgrave \& C. Contandriopoulos (Eds.), Architectural theory. Vol. II: An anthology from 1871 to 2005 (pp. 566-568). Malden, MA: Blackwell.

Perez-Gomez, A. (1994). Architecture and the crisis of modern science. Cambridge, MA: MIT Press.

Pollitt, J. J. (1972). The classical moment. In: Art and experience in classical Greece (pp. 64-110). London: Cambridge University Press.

Popp, T. (2009). An architect walks into the lab. Pennsylvania Gazette, January-February, 31-39.

Poster, M. (2001). What's the matter with the Internet? Minneapolis: University of Minnesota Press.

Rovai, A. (2002). Building sense of community at a distance. International Review of Research in Open and Distance Learning, 3(1), 1-12.

Simon, H. (1996). Understanding the natural and artificial worlds. In: Sciences of the artificial (pp. 1-23). Cambridge, MA: MIT Press.

Speaks, M. (2005). After theory. Architectural Record, June, 73-75.

Strauss, A. (1987). Qualitative analysis for social scientists. New York: Cambridge University Press.

Summerson, J. (1966). The language of classical architecture. Cambridge, MA: MIT Press.

Technology and geography (special report). (2012, October 27). The Economist.

Threadless. (n.d.). Retrieved November 19, 2012, from http://beta.threadless.com/make/.

Tzonis, A., \& Lafaivre, D. (1975). The mechanical body versus the divine body: The rise of modern design theory. Journal of Architectural Education, 29, 4-7.

UrbanSim. (2009, May 9). Retrieved February 13, 2012, from http://www.urbansim.org/Main/UrbanSim.

Vitruvius. (1960). On symmetry: In temples and in the human body (Book III/1). In: The ten books on architecture (M. H. Morgan, Trans.; pp. 73-75. New York: Dover.

Wang, D. (2008, Fall). The New Virtualism: Beijing, the 2008 Olympic Games, and a new style for world architecture. Washington State Magazine, 7(4), 32-35. Retrieved November 10, 2012 from http://wsm.wsu.edu/stories/2008/Fall/WSM-Aug08.pdf.

Wang, D. (2009). Kuhn on architectural style. Architectural Research Quarterly, 13(1), 49-57.

Yeang, K. (2011). Green design: From theory to practice. London: Black Dog.

\footnotetext{
Notes

1 "Product Service Systems" is an emerging field of study. The focus is on designing systems of business delivery in which both the product sold and the system in which it serves (in production, sales, use, recycling, etc) is designed to be less materialintensive and beneficial to overall life-cycle costs. I was first made aware of this literature by my doctoral student, Maryam Afshar. Representative articles include the following: Goedkoop, M. J., van Halen, C. J. G., te Riele, H. R. M., \& Rommens, P. J. M. (1999). Product service systems, ecological and economic basis: PricewaterhouseCoopers, N.V. / Pi!MC, Storrm C. S., Pre consultants; Tan, A. R., \& McAloone, T. C. (2006, May). Characteristics of strategies in product/service-system development. Paper presented at the International Design Conference, Dubrovnik, Croatia. Retrieved November 19, 2012, from http://orbit.dtu.dk/fedora/objects/orbit:46864/datastreams/file_2509203/content.

${ }^{2}$ This is the discernment of Critical Regionalism, which we can take as one of the ballasts reacting against the potential erasure of locality that the computer-cyber epiphore can easily bring forth.
} 
3 "Spirit" is defined as "the feelings of friendship, cohesion, and bonding that develop among learners as they enjoy one another and look forward to time spent together" (Rovai, 2002, p. 4).

4 In this context I should note Nel Janssen's doctoral dissertation, "Utopia-Driven Projective Research," defended at Chalmers University School of Architecture, Gothenburg, Sweden, in June 2012. I acted as Janssen's external opponent. Janssen's research did not engage much with the computer. But one of my points to her at her defense was that her argument for "projective" research in which the goal of the design process is to envision future environments at large urban and regional scales can be greatly energized by computer technology. 